\title{
La internalización de la naturaleza autónoma en la sociedad ${ }^{1}$
}

\section{Raymond Murphy}

University of Ottawa. Department of Sociology

murphy@uottawa.ca

\section{Resumen}

En la actualidad, existe una gran cantidad de discursos teóricos que declaran que la naturaleza está siendo socialmente construida e incluso abolida. Unos autores lo celebran, otros se lamentan por ello, mientras que otros terceros incluso apartan las dinámicas naturales totalmente de sus análisis. En este artículo, se evalúan, en primer lugar y de forma crítica, estas distintas teorías y metodologías referentes a las relaciones entre las prácticas sociales y los procesos naturales, para desarrollar a continuación un argumento alternativo. La expansión de la sociedad hacia áreas vírgenes ha ocasionado la aparición de nuevos trastornos de la naturaleza a la sociedad. La naturaleza prístina ha sido sustituida por una naturaleza primaria modificada socialmente, que conserva su capacidad de afectar a las construcciones sociales con dinámicas independientes. Sin embargo, la naturaleza permanece encajada dentro la tecnología ${ }^{2}$, así como su potencial para escapar al control. Estos híbridos construidos por humanos y no humanos se recombinan con procesos y materiales de la naturaleza. Ahora que esta naturaleza recombinante ha sido integrada en la sociedad y que nuevas dinámicas de la naturaleza primaria han sido internalizadas, hay un mayor motivo para incorporar las fuerzas de la naturaleza en los análisis sociológicos.

Palabras clave: realismo crítico, construccionismo, naturaleza primaria, naturaleza recombinante, tecnología.

\section{Abstract. The internalisation of autonomous nature into society}

There is presently much theoretical discourse claiming that nature is being socially constructed or even abolished. Some authors celebrate this development and others lament it. Still others bracket natures dynamics out of the analysis. The present paper critically assesses these theories and methodologies concerning relations between social practices and processes of nature. It then develops an alternative argument. The expansion of society into wilderness areas has brought new disturbances of nature into society. Pristine

1. Originalmente publicado, y traducido con permiso, en The Sociological Review, 50 (2002): 313-333. Este trabajo fue presentado por el autor en el Institut de Ciència i Tecnología Ambiental de la UAB en enero del 2005. Traducido por Feliu López Gelats y revisado por David Tàbara. Esta traducción ha contado con el apoyo financiero del Departamento de Sociología de la Universidad de Ottawa, Canadá.

2. Nota del traductor: Y, pues, no eliminada ni abolida, sino solamente transformada. 
nature has been replaced by socially encompassed primal nature, which retains its capacity for independent dynamics that affect social constructions. Moreover, nature remains embedded in technology and so does its potential to escape control. These hybrids constructed by humans and nonhumans recombine processes and materials of nature. Now that this recombinant nature has been integrated into society and new primal dynamics of nature have been internalised, there is increasing reason to incorporate the forces of nature into sociological analysis.

Key words: critical realism, constructionism, primal nature, recombinant nature, technology.

\section{Sumario}

1. La construcción social, abolición, dominio, muerte o final de la naturaleza

2. Debilidades

3. Realismo crítico
4. La internalización de la naturaleza autónoma en la sociedad

5. Conclusión

Bibliografía

\section{La construcción social, abolición, dominio, muerte o final de la naturaleza}

En la actualidad, se dan fuertes corrientes de discurso en las ciencias sociales declarando que la naturaleza está siendo construida socialmente, que ha sido abolida, o que es mejor apartar las dinámicas de la naturaleza de los análisis. Este artículo empieza con una crítica de estas teorías y metodologías, para luego proceder a desarrollar el argumento opuesto, es decir, que una naturaleza autónoma ha sido internalizada en la sociedad y que, por lo tanto, lo adecuado en sociología es precisamente analizar las relaciones entre las prácticas sociales y las dinámicas de la naturaleza.

Como ejemplo de estas posiciones, en su teoría sobre la modernidad tardía, Giddens (1991: 224) sostiene que la «invasión del mundo natural por sistemas abstractos implica el final de la naturaleza como un dominio externo al conocimiento e implicación humana». Beck (1995: 37-8) mantiene que el "proceso de interacción con la naturaleza la ha consumido, abolido [...] ya no existe más».

Por otro lado, Eder (1996: 20) ha contribuido a convertir la sociología en una teoría cultural «que concibe la naturaleza como construida socialmente». Continuando con esta premisa, él solamente concibe y examina el discurso sobre la naturaleza, no la naturaleza como un entramado de dinámicas autónomas. El libro de Eder es tan sólo uno entre muchos trabajos de los socialconstruccionistas (Latour y Woolgar, 1986; Evernden, 1993), que afirman que el aparente mundo natural ha sido producido de muchas maneras por prácticas sociales. Hay también versiones más suaves de construccionismo que admiten la existencia independiente de las dinámicas naturales, pero escogen separarlas del análisis (Capek, 1993; Lidskog, 1996; Macnaghten y Urry, 1998) o 
simplemente lo pasan por alto en el análisis implícitamente (Hannigan, 1995; Grundmann, 2001).

El postmoderno Bluhdorn (1997: 125-47) declara que la naturaleza ha sido abolida. Con esto quiere decir que 1) la naturaleza prístina ha sido transformada en naturaleza modificada por los seres humanos y 2) la noción de naturaleza como lo Otro de la sociedad ha sido eliminada. Por lo tanto, la distinción entre naturaleza y sociedad tiene que abandonarse, y ahora natural equivale a social. La naturaleza como una sola entidad independiente de la civilización humana ha sido sustituida por múltiples naturalezas: una pluralidad de construcciones sociales que contienen tanto la naturaleza física como su significado, los cuales compiten y a menudo se excluyen mutuamente. Según Bluhdorn, la conciencia ambiental viene siempre y exclusivamente desencadenada por la violación de normas culturales, nunca por la parte material. Mediante esta suposición, trata de emancipar la teoría postmodernista y la política postecologista de los imperativos ecológicos. No tiene como objetivo solucionar la crisis ecológica, que ve como una crisis ideológica.

Las teorías de la construcción social de la naturaleza, de su abolición y de la primacía de los designios humanos sobre los límites naturales, no son creaciones originales de los años noventa ni tampoco surgieron de la nada. Todo lo contrario, se trata de una continuación de las ideas de los períodos tempranos de la modernidad. Durante generaciones, el desarrollo tecnológico había progresado bajo la premisa de transformar, incluso sustituir, al mundo natural (Worster, 1994: 350). Tenner (1997: 348-9) argumenta que fue especialmente durante el imperante optimismo tecnológico del periodo comprendido entre 1860 y 1960 que los europeos y los norteamericanos, republicanos y comunistas, creyeron que podrían reconstruir la naturaleza, a la vez que fracasaron en el momento de percibir sus propias creaciones emergentes. Esta ideología persistió, sin embargo, más allá de 1960. En 1974, Beckerman (1974) sostenía que el hombre, más que la naturaleza misma, proporciona a la naturaleza las características que posee; por lo tanto a medida que la razón se desarrolle, los recursos crecerán en lugar de agotarse. Al mismo tiempo, el editor industrial de New Scientist declaraba que los humanos ya no están sujetos a las limitaciones naturales: «La tecnología puede alcanzar prácticamente cualquier cosa hoy en día si invertimos lo suficiente en ello. La tecnología proporciona al hombre poderes sin parangón sobre su medio ambiente y él mismo» (Hamilton, 1973: 41). Simon (1981) desprecia el riesgo de agotar los recursos argumentando que los humanos disponen del recurso esencial: la razón. La suposición que la naturaleza podría ser reconstruida socialmente sin límite fue parte de la ofensiva antiecologista durante la era Reagan en los Estados Unidos de América, en contra de la idea de los límites ecológicos (Mitchell, 1990; Dunlap y Scarce, 1991; Dunlap y Catón, 1993).

Así, el director general de los Servicios Sanitarios Públicos de los Estados Unidos de América creía en la abolición de una parte de la naturaleza en 1967, cuando afirmó que era el «momento de cerrar los libros sobre enfermedades infecciosas» (citado en Tenner, 1997: 74). Incluso, cuando el sida apareció por 
primera vez, había un gran optimismo en que los deseos humanos rápidamente abolirían esta dinámica emergente de la naturaleza. «El presidente y director ejecutivo de Merk declaró, en 1988, que la compañía esperaba encontrar un fármaco anti-sida en cinco años» (Tenner, 1997: 81). En todo el ilustrado período de desarrollo de la ciencia, la industrialización, y la modernidad - y no sólo ahora-, se asumía que la razón capacita a la humanidad para escapar de las fuerzas de la naturaleza y las reconstruye socialmente, conduciendo a la ascensión de lo cultural y de lo social sobre la naturaleza. Grundmann (1991a, 1991b) fundamenta su construccionismo sobre el postulado que la tecnología proporciona poderes casi ilimitados para superar las limitaciones de la naturaleza y dominarla.

En 1980, Merchant también advirtió de la Muerte de la naturaleza a manos de la ciencia y de la razón moderna, masculina e instrumental, que trata de subyugarla. A diferencia de partidarios de los paradigmas anteriores, Merchant claramente veía que se trataba de una posibilidad nociva y trató, mediante su advertencia, de promover acciones para evitarlo. En 1990, McKibben (1990) declaraba que el Final de la naturaleza había llegado. La naturaleza prístina ya no existe: cada rincón de nuestro planeta ha sido ya modificado por humanos. Este cambio era visto como una pérdida y peligrosa. Este cambio ha sucedido como resultado no sólo de intencionados asentamientos humanos en áreas anteriormente vírgenes, sino también debido a involuntarias consecuencias nocivas de la actividad humana, como es el caso de la lluvia ácida y el cambio ambiental global de origen antropogénico. En este "mundo postnatural» (McKibben, 1990: 55), los humanos se han enredado en la labor de gestionar el planeta, una tarea que prevé tan compleja que, sin duda, faltará capacidad técnica y científica. Él sostenía que el cambio material estimulaba también un cambio cultural: «no podemos imaginar más que formamos parte de algo mayor que nosotros mismos» (McKibben, 1990: 78) y "no hay nada excepto nosotros" (McKibben, 1990: 55). Como consecuencia de la necesidad humana por la naturaleza, tanto a nivel material como cultural, McKibben trató de promover un nuevo comienzo de la naturaleza: su renacimiento.

\section{Debilidades}

\subsection{Naturaleza merodeando entorno y dentro de las construcciones sociales}

A pesar de que el argumento que los humanos están construyendo socialmente la naturaleza o que incluso la están aboliendo es atractivo en lo superficial debido a los logros de la ciencia, la tecnología, la razón y la organización social, este argumento se torna débil cuando nos adentramos a examinarlo a niveles más profundos. «Las cosas devuelven el mordisco», tal y como Tenner (1997) ha documentado, y una de las principales razones de ello es porque las construcciones sociales se encuentran en continua interacción con todo aquello que es dinámico, emergente, infinito, y con todos los procesos naturales que son solamente parcialmente conocidos, tanto dentro como fuera del cuerpo humano. 
Poco sabía el director general de los Servicios Sanitarios Públicos de los Estados Unidos de América que estaba considerando como un libro cerrado a las enfermedades infecciosas en vísperas del brote de infección del VIH. "Donde una vez quisimos erradicar, estamos ahora luchando por manejar» (Colborn y otros, 1996: 241-2). Esto no es para despreciar el éxito de la sociedad moderna en su lucha contra la infección del VIH, que ha sido gestionada y mantenida como una epidemia crónica en lugar de una epidemia mortífera. Enfermedades infecciosas como el VIH, sin embargo, no han sido erradicadas. «En 1992, él [el director ejecutivo de Merck, quien se jactó de encontrar un fármaco antisida en cinco años] reconoció para el Wall Street Journal su "enorme decepción". Las rápidas mutaciones del VIH, como es el caso de otros virus, parecen tornar la erradicación en casi imposible» (Tenner, 1997: 74). Del mismo modo que la sociedad moderna ha tenido poco éxito en abolir o reconstruir las perturbaciones naturales de gran escala - como terremotos, volcanes, huracanes y tormentas de hielo—, sólo puede manejar sus consecuencias mediante avisos, evacuaciones y refugios.

De este modo, es más razonable hablar de la manipulación de la naturaleza que de su construcción. Esta manipulación conduce a la aparición de nuevos riesgos y, como Beck (1992) argumenta, surge una nueva sociedad del riesgo precisamente porque la naturaleza retiene su poder. Beck (1995: 50-1) defiende que si la amenaza de toxicidad se niega «sólo queda la construcción social de no toxicidad. Esto no desinhibe el efecto, sino solamente su designación. [...] Esto pudiera representar una consolación momentánea, pero no ayuda contra el envenenamiento». La naturaleza y sus dinámicas continúan escondiéndose alrededor y dentro del construccionismo social, incluyendo la teoría de Beck. Abolición no es un nombre apropiado cuando se aplica a la naturaleza. Solamente la naturaleza prístina fuera de la sociedad ha sido abolida y consumida: «la naturaleza ya no puede ser más entendida como fuera de la sociedad, o la sociedad como fuera de la naturaleza» (las cursivas son de Beck, 1992: 80). Cabe remarcar que él argumenta que la sociedad ya no puede entenderse más fuera de la naturaleza, lo que no tendría sentido si la naturaleza estuviera abolida. Su afirmación es lógica en términos de lo que Adam (1995: 148) llama «la interpretación fundamental de la naturaleza y la cultura». Más que una fuera de la otra o la abolición de la naturaleza, ella sostiene convincentemente que las ciencias sociales necesitan concentrarse en el estudio de esta interpretación.

\subsection{Confundir "lo externo» $y$ "lo autónomo» en lo "otro» 3}

Aunque, en nuestro planeta, prácticamente ya no queda naturaleza inalterada por construcciones humanas, sería erróneo considerar que no hay en la naturaleza nada más que su estado prístino. La naturaleza ahora desencadena

3. Nota del traductor: otherness. 
sus propios procesos independientes y emergentes dentro de la sociedad, en lugar de hacerlo en lo salvaje y lo virgen, ya que la actividad humana se ha expandido y afecta al conjunto de la biosfera. Lo que viene siendo verdad dentro del cuerpo humano (como cualquiera con cáncer o fibrosis quística comprueba) y en ecosistemas locales habitados por sociedades, es ahora verdad a escala planetaria. Que la naturaleza no esté separada de la sociedad no reduce su carácter como lo otro respecto a la sociedad. La eliminación de una naturaleza externa sobre la Tierra no debe ser confundida con la abolición de una naturaleza autónoma. La naturaleza conserva su carácter independiente a pesar de que los humanos traten de controlarla y que crecientes construcciones sociales internalizen las dinámicas naturales en la sociedad. A medida que las construcciones humanas modifican los mecanismos de autorregulación de la naturaleza e invaden lo virgen y lo salvaje, los procesos naturales emergentes invaden a la sociedad humana para operar conjuntamente con las anteriores fuerzas. Lo otro aún está entre y dentro de nosotros, a pesar de que la naturaleza se ha convertido en lo otro mediante el funcionamiento de sus procesos autónomos en el seno de la sociedad, más que fuera de ella, en lo prístino y salvaje.

Sin embargo, la expresión de que la naturaleza "no está allá fuera» se ha tornado ambigua. El fragmento de naturaleza que se encuentra sobre o cerca de nuestro planeta ha sido incorporado a la sociedad mediante la expansión de las construcciones humanas y, por lo tanto, ya no está «allá fuera», en el sentido de ser externo a la sociedad. Sin embargo, permanece "allá fuera» si ello significa autónomamente en lugar de hacerlo como una construcción social. La ambigüedad encuentra su camino en los análisis sociológicos. Por ejemplo, un libro que utiliza 276 páginas reduciendo la naturaleza a un grupo de nociones confrontadas termina, sin embargo, con una línea alertando que las corporaciones y los estados pueden «desencadenar la ferocidad de la naturaleza, que puede tomarse la venganza de la sociedad humana y no dejar nada de nada para los futuros ciudadanos globales para sentir como todas las naturalezas confrontadas llegan a su fin» (Macnaghten y Urry, 1998: 277). Parece mejor, pues, integrar la naturaleza virgen en los análisis antes del apocalipsis que simplemente mencionar su importancia en una línea dejada caer al final de un libro que la descarta de su análisis.

Las continuas sorpresas que nos ofrece la naturaleza demuestran que los sistemas abstractos no han hecho llegar a su fin a la naturaleza como un dominio externo al conocimiento humano. La ignorancia y la incertidumbre, más que el conocimiento, continúan caracterizando muchas de las relaciones entre los sistemas abstractos construidos socialmente y las dinámicas naturales, ya sea el caso que éstas involucren moléculas proteínicas de priones, acontecimientos climáticos extremos o la desaparición de anfibios. Claramente, Giddens estaba exagerando. 


\subsection{Confundir concepciones de la naturaleza con el referente}

Hay muchos significados de la naturaleza enfrentados. Los construccionistas tienden a usar indistintamente lo que «es» y lo que «significa» —igualando «lo que esto "es" realmente a lo que significa, ya que está socialmente construido" (Burningham y Cooper, 1999: 308) — y a menospreciar todo excepto los significados. El análisis de Eder trata de la construcción social, y no de la naturaleza en sí, sino más bien de concepciones de la naturaleza, como por ejemplo «la naturaleza Protestante» (1996: VIII). Éste es un tema mucho más restringido que el supuesto análisis acerca de las interacciones entre la naturaleza y la sociedad. A pesar de que los significados otorgados a las dinámicas naturales por los humanos se construyen socialmente, estas dinámicas no pueden ser reducidas a meros significados, pues poseen autonomía por ellas mismas, y ejercen sus efectos sobre los humanos y sus construcciones sociales sin tener en cuenta los significados que los humanos les asignan. Tanto la experiencia como la evidencia científica llevan a la conclusión de que las dinámicas de la naturaleza son más que manchas de tinta de una lámina Rorschach, donde únicamente las distintas interpretaciones construidas socialmente tendrían consecuencias. La naturaleza no puede reducirse a lo que la gente piense de ella (ver Murphy, 1999). La concepción que restringe la naturaleza a fenómenos puramente culturales, la supuesta construcción social de la naturaleza, y más aún la de la abolición de la naturaleza, constituyen una «visión de la naturaleza demasiado socializada» (Benton, 1994: 45), así como una "epistemología demasiado socializada» (Schmidt, 2001: 142). Las concepciones de la naturaleza deben distinguirse claramente de los referentes (Sayer, 1997), con el fin de dejar lugar en los análisis a las sorpresas de la naturaleza, a la impredictibilidad de sus dinámicas y a la incertidumbre e ignorancia humana. Estas concepciones deben situarse en prácticas relacionales concretas, lo que incluye relaciones con las dinámicas del mundo material. Sin embargo, los significados son importantes, en el sentido de que los significados adecuados promueven la realización de evacuaciones, códigos de edificios seguros y prácticas preventivas, mientras que significados inapropiados no lo hacen.

\subsection{Abstraer las prácticas sociales fuera de su contexto material}

Las creaciones de la naturaleza sustentan las construcciones sociales. Por ejemplo, los hábitos de alimentación no son puramente fenómenos culturales, tal y como implica el análisis de Eder. Éstos se han desarrollado en un contexto material gobernado por dinámicas naturales. Las culturas aprenden lo que es apropiado para el aparato digestivo a partir de lo que la naturaleza les ha facilitado, de otro modo, desaparecen. A no ser que la cultura vuelva ciegos a los humanos con respecto a los requerimientos naturales (lo que puede ocurrir), los procesos de la naturaleza influencian la acción y el pensamiento. Este hecho se ha ido intensificando bajo la modernidad a medida que alimentos probados durante milenios son sustituidos por alimentos modificados genéticamente 
o por alimentos producidos utilizando fertilizantes artificiales, pesticidas, antibióticos o productos químicos para incrementar su atractivo. La manipulación de la oferta alimenticia presenta nuevas dinámicas naturales y nuevos riesgos emergentes, como son los suplementos hiperproteicos —ilustrados por el fenómeno EEB/Enfermedad de Creutzfeldt-Jacob. Las teorías construidas como si existiera una cultura general culinaria independiente de los procesos naturales son tan débiles como sus opuestas: el esencialismo biológico.

Bluhdorn (1997) disuelve la distinción entre naturaleza y sociedad mediante, de un modo arbitrario, la acción de percibir únicamente prácticas sociales. «Naturaleza = sociedad» es su fórmula para reducir la naturaleza a lo social, lo que oscurece las dinámicas físicas que no pueden ser reducidas a construcciones sociales, así como también oscurece los efectos de estas dinámicas sobre las construcciones sociales. Su proclamado enfoque "postdualista», "postecologista» considera el entorno físico como una realidad irrelevante, hipotética en las políticas ambientales. Así pues, abstrae estas políticas fuera de sus contextos materiales. Consecuentemente, esta variante del postmodernismo lleva a cabo un trabajo parcial, sobre todo cuando analiza el discurso de la sociedad, y particular, sobre ecología. Adam (1995: 126) ha demostrado convincentemente, mediante su investigación, que la exclusión de la naturaleza de los análisis de cultura no se sostiene y que los discursos y las prácticas sociales deben ser analizados en el contexto de los ritmos del cuerpo y del planeta.

\subsection{El fracaso asumido en las predicciones del daño ecológico}

Postmodernistas como Bluhdorn declaran que las profecías acerca del daño ecológico no se han hecho realidad. Lejos de ser originales, esta afirmación es equivalente a la de esos modernistas que han despreciado alarmas ecológicas como El sindrome del día del Juicio Final (Maddox, 1972), declarando que el Día del Juicio Final ha sido cancelado (Vayk, 1978) y que interpretaron la preocupación por el riesgo tecnológico como una fobia patológica (Sjoberg, 1987). Muchos elementos del argumento postmoderno sobre la abolición de la naturaleza se parecen en gran medida al argumento que predominó anteriormente durante la modernidad acerca de su dominio. En este sentido, el postmodernismo es una extensión del modernismo; la continuidad es más destacable que cualquier discontinuidad que pueda existir. El post-confunde.

El alegado fracaso de la profecía ecológica ignora proyecciones validadas por la experiencia y/o la ciencia. Algunos ejemplos de ello son la esquilmación de las pesquerías, la deforestación, la lluvia ácida, la acumulación de pesticidas y fertilizantes en el suelo, la erosión y la desertificación, la escasez de agua potable y el agotamiento de los acuíferos, la acumulación de gases de efecto invernadero en la atmósfera, el rápido crecimiento de la población humana, la pérdida de hábitats, la extinción de especies, la desaparición de anfibios, etc. Más preocupante aún es el peligro sobre el cual los ecologistas han venido alertando: la matriz de problemas resultante de la interacción de todos ellos (el efecto némesis). 
Algunos riesgos han sido mitigados precisamente porque las alarmas ecológicas han actuado como profecía que se refuta a sí misma. El riesgo fue reconocido como real y esta previsión llevó a la acción que, de modo exitoso, disminuyó la amenaza. Muchas naciones industrializadas hicieron frente a una grave contaminación de sus lagos y ríos y tomaron medidas para tratarla. Las naciones reconocieron la amenaza que suponía los CFC para la capa de ozono y firmaron el Protocolo de Montreal, que redujo sus producciones, de este modo disminuyó la destrucción de la capa de ozono. La deforestación en Brasil se encontraba en una curva ascendente a principios de 1980, entonces las alertas ecológicas fueron tomadas en serio, como consecuencia la destrucción de su selva tropical se ha desacelerado. En donde la amenaza de terremotos ha sido reconocida, los edificios han sido reforzados, y el número de muertos ha caído en picado (Zebrowski, 1997).

\subsection{Las implicaciones del relativismo}

Algunos postmodernos llevan el relativismo demasiado lejos. «Si las ballenas se extinguen, éste es un simple hecho que, por sí mismo, no es ni positivo ni negativo. Si los desiertos se expanden y algunas inundaciones ahogan a millares de personas en Bangladesh, nosotros podemos o no encontrar este hecho trágico» (Bluhdorn, 1997: 133). Los problemas ambientales se desvanecen en este discurso postmoderno y son sustituidos por una charla sobre el cambio ambiental: «el cambio ambiental físico continuará como antes, pero después de la abdicación del mismo tema no habrá ningún punto de vista desde el cual cualquier cosa que pueda suceder empíricamente pudiera, con la declaración de validez que sea, ser descrito o criticado como problemático o incluso catastrófico» (Bluhdorn, 1997: 138). Las implicaciones de considerar que las múltiples representaciones conceptuales del cambio ambiental son igualmente legítimas va de perlas, ideológicamente, para los productores de lluvia ácida, gases de efecto invernadero, CFC y otros contaminantes. A la industria química le encanta oír que su discurso sobre el DDT es tan legítimo como el de Rachel Carson (1962). Lo mismo ocurre con respecto a los contaminadores que descuentan el futuro en favor de intereses actuales, como hace este discurso postmoderno. «En una sociedad postnatural, la preocupación por el futuro se torna incluso más absurda porque el proceso evolutivo, y su aceleración del cambio, continuamente invalida los criterios de toma de decisiones que son aplicables, por tanto, exclusivamente al presente» (Bluhdorn, 1997: 142).

Los constructivistas sostienen que su enfoque no descarta importantes medios intelectuales para tratar los problemas ambientales: «Todo lo que se ha quitado es la capacidad de fundamentar los argumentos propios de cada uno o desacreditar los argumentos opuestos comparándolos desfavorablemente con la realidad objetiva» (Burningham y Cooper, 1999: 310-1). Pero esto les quita el as de la manga a los ecologistas. Echar fuera la realidad de la destrucción de la capa de ozono es precisamente lo que la industria química trató de hacer y empleó gran cantidad de recursos para intentar refutar declaraciones sobre esta 
destrucción. Los científicos sólo pudieron ganar a la industria química porque ellos tenían una destrucción de capa de ozono por descubrir y presentar. Si los construccionistas quieren hacer frente a la degradación ambiental, entonces no es muy ingenioso oscurecer lo que las medidas miden. Ya que la carga de la prueba se encuentra en los ecologistas que tienen que demostrar la existencia del daño ambiental, pues la opción por defecto es continuar como siempre, ser agnóstico acerca de la realidad de los problemas ambientales favorece los contaminadores y corroe al ecologismo y el medio ambiente. Donde los construccionistas tratan de apoyar a los ecologistas, lo hacen de un modo muy débil, al desacreditar el más poderoso argumento de la realidad sobre la degradación ambiental, lo cual deja una base muy pequeña desde la que criticar. Manifestar que cualquier declaración —a favor o en contra- está construida socialmente y debe ponerse en duda, proporciona un apoyo anémico.

Remarcar la correspondencia entre el discurso relativista y los intereses de los contaminadores no significa que estas teorías estén siendo rechazadas en términos políticos. Las teorías de la construcción social de la naturaleza y su abolición son deficientes en términos analíticos y empíricos, tal y como demuestra este artículo en otras partes y también en Murphy (en próxima publicación). Además, las demandas de la industria no son excluidas a priori. En muchos casos, la plausibilidad de las demandas de la industria y de los ecologistas no se conocen al principio. Sin embargo, sí que se conocen después de un período (Adam, 1995, 1998, 2000) en el campo de pruebas de las dinámicas de la naturaleza mediante la experiencia, la observación y/o la ciencia. Sería ingenuo ignorar los intereses de los contaminadores cuando niegan y relativizan las declaraciones de degradación ambiental.

\subsection{Construccionismo extremo, suave y realista}

Existen diferentes variantes de construccionismo social (Sismodo, 1993; Burningham y Cooper, 1999). El construccionismo extremo (Latour y Woolgar, 1986; Woolgar, 1988; Eder, 1996) defiende que la realidad y la naturaleza son construcciones mentales, por lo tanto, sigue pretensiones idealistas (ver Dickens, 1992: 176-7). Los construccionistas suaves (Capek, 1993; Lidskog, 1996; Macnaghten y Urry, 1998) admiten que las dinámicas naturales son independientes de las concepciones, pero rechazan examinar las relaciones entre las dinámicas naturales y las prácticas sociales por razones estratégicas, lo cual resulta en una debilidad similar al hecho de suponer que la naturaleza no existe. Los humanos son tratados como espíritus puros en un vacío material, más que como criaturas vivientes que experimentan, sienten y aprenden en un contexto de dinámicas naturales independientes (Schmidt, 2001: 141-2). A pesar de que los estudios empíricos realizados por los construccionistas proporcionan información útil acerca de cómo las construcciones sociales se negocian, su postura programática no les permite observar las complejas relaciones existentes entre las construcciones sociales y las construcciones naturales. En alguna parte de este continuo entre los construccionistas suaves y los extremos, 
metodológica y ontológicamente, yace la suposición que «el mundo natural tiene un papel muy pequeño, sino inexistente, en la construcción del conocimiento científico» (Collins, 1981: 3). Esta pretensión con poco fundamento de Collins oscurece la especificidad de la ciencia y la ciencia aplicada, de sus logros y peligros, lo que conlleva que su construcción se perciba de modo similar a «la construcción de lo paranormal: nada no-científico tiene lugar» (Collins y Pinch, 1979). Murdoch (2001: 117) argumenta convincentemente que esto «mina la habilidad del sociólogo de dar cuenta del poder de la ciencia moderna».

Una tercera variante del construccionismo ha sido llamada "construccionismo realista» (Murphy en próxima publicación). Ésta integra el tema de la validación de declaraciones en el análisis, aunque implícitamente. Por ejemplo, el estudio de Grundmann (2001) remarca la importancia de las inteligentes mediciones de la destrucción de la capa de ozono científicas. En tanto que estas mediciones no se hubieran asumido como arbitrarias y sin fundamento, entonces las propiedades de la capa de ozono afectaban lo que se percibiría por los científicos y, a través de sus observaciones, esto afectaba a las negociaciones del Protocolo de Montreal. Por debajo de la controversia científica, existe una realidad material que conduce a que algunas hipótesis sean más convincentes que otras, como es el caso de la destrucción material de la capa de ozono, en lugar de creer que se está expandiendo. El construccionismo de Grundmann le previene de haber de incorporar explícitamente en su estudio las propiedades cambiantes de la capa de ozono, pero al menos están ahí implícitamente. Hannigan va más allá hacia el realismo: «el construccionismo social, tal y como es conceptualizado aquí, no niega los poderes causales independientes de la naturaleza, sino más bien afirma que el orden de posiciones de estos problemas por los actores sociales no siempre corresponde directamente a la necesidad efectiva» (Hannigan, 1995: 30). Esto implica la necesidad de integrar en el análisis en lugar de poner entre paréntesis «los poderes causales independientes de la naturaleza» y estudiar la correspondencia y la no correspondencia entre el ordenamiento de problemas y la necesidad efectiva, lo que Hannigan lleva a cabo hasta cierto punto. La fortaleza de estos dos trabajos ilustra que, cuanto mayor sea el apuntalamiento realista que adopta el social construccionismo, más fuerte se vuelve.

\section{8. ¿Los peces vuelan o nadan?}

Burningham y Cooper (1999) tratan de defender todas las variantes del construccionismo citando la declaración de Tester (1991: 46) que «un pez es solamente un pez si está clasificado socialmente como tal [...] los animales de hecho son una hoja en blanco en la que puede inscribirse cualquier mensaje, cualquier significado simbólico que se desee socialmente» y este pez podría ser clasificado de otro modo. Estoy de acuerdo con Tester, pero disconforme con la ilógica inferencia que hacen Burningham y Cooper (1999: 309) «que la indudable restricción sobre la flexibilidad interpretativa deriva aquí de cate- 
gorizaciones preexistentes, más que de cualquier realidad natural o física dada». $\mathrm{Su}$ «más que» es engañoso y ejemplifica la voluntad del construccionismo social de menospreciar las dinámicas naturales. Podría haberse construido socialmente la idea que el pez tiene alas y puede volar. Quizás alguien en la historia lo haya hecho. Pero la tendencia dominante ha sido la de construir el significado que el pez no tiene alas y no puede volar. ¿Por qué? Esto es así porque la dinámica de la naturaleza conduce a restricciones en la flexibilidad interpretativa a través de la observación, la experiencia, y la ciencia como un modo refinado y sistemático de observación y experiencia. Las propiedades físicas del pez, creadas por las dinámicas autónomas de la naturaleza, conducen a que la gente tienda a atribuir estas propiedades al pez en lugar de las opuestas, a pesar de que la gente podría hacer lo contrario. Los seres humanos no están ciegos. Los humanos son seres sensitivos que experimentan un mundo material. Quitando las dinámicas naturales del análisis, ya sea por razones ontológicas, metodológicas o estratégicas, los construccionistas han dejado de considerar una influencia significativa sobre las percepciones, las concepciones y las prácticas sociales. Tiene menos sentido quitar las dinámicas naturales del análisis de los problemas ambientales que quitar las desigualdades reales del análisis de las clases sociales.

Cabe remarcar que flexibilidad interpretativa no implica flexibilidad de consecuencias. Categorías preexistentes y cultura, incluso experiencias previas, pueden conducir a la gente a construir significados (como percepciones de riesgo) que sean inapropiadas para las dinámicas naturales. A estos les coge por sorpresa y sufren las consecuencias (Soper, 1995: 159). La sociedad que construye socialmente el significado que dar de comer entrañas de ovejas es bueno para el ganado y que la encelopatía esponngiforme bobina (EEB) no puede transmitirse del ganado a los humanos tiene mucho en común con la persona que inscribe pez con el mensaje que puede volar, lo cual lanza uno fuera del agua al precipicio. Pobre pez, pobre sociedad. La inflexibilidad de las consecuencias en las relaciones entre los significados construidos socialmente y las dinámicas autónomas de la naturaleza es precisamente lo que genera las restricciones de la naturaleza sobre la flexibilidad interpretativa.

Burningham y Cooper (1999: 309) tratan de salvar el construccionismo extremo entendiéndolo "como un cuestionamiento a las demandas de validez ontológica per se», pero esta hipocresía usurpa la declaración que el pez puede nadar al igual que la afirmación que el pez puede volar, e igual la declaración que los CFC destruyen la capa de ozono con la declaración de la industria química que los CFC no afectan para nada a la capa de ozono. Poner en duda la validez de declaraciones es útil para la promoción de investigaciones para determinar si éstas son válidas. Sin embargo, el rechazo a integrar en el análisis que algunas declaraciones que tienen una validez mayor que otras en términos de su coherencia con las dinámicas de la naturaleza construye socialmente malentendidos. 


\section{Realismo crítico}

Hannigan (1995: 38-9) recuerda que Coleman y Cressey «ilustran la definición construccionista de un problema social remarcando que «la contaminación no fue un problema social hasta que los activistas ecologistas fueron capaces de convencer a otros de que mostraran su preocupación con respecto a unas condiciones que, de hecho, ya existían desde hacía un tiempo». Sin embargo, ellos socavan esta argumentación preguntándose: «Si millares de personas no sabían que estaban siendo envenenadas por fugas radiactivas procedentes de una planta de energía nuclear, continuaría la contaminación radioactiva siendo un problema social?». Colemann y Cressey, no obstante, van más allá del simple guión constructivista de que no existe un problema social hasta que no existe preocupación. Ellos, así como Adam (1995, 1998, 2000), consideran que un problema material para una comunidad puede existir basado en la dinámica autónoma de la naturaleza antes de que el riesgo sea reconocido, y que esto constituye un problema social latente. Este período de riesgo no percibido es particularmente peligroso, pues no se toman medidas para transformar las prácticas sociales para corregir el problema material. Dickens (2001: 93-4) da el ejemplo de la transmisión de la EEB de ganado vacuno a los seres humanos, que atacó a la mente humana mucho antes de que el riesgo fuera percibido como real y produjera catastróficas consecuencias sociales en Gran Bretaña. Soper (1995: 158) distingue entre niveles superficiales y profundos de naturaleza, lo que implica la necesidad de diferenciar entre concepciones actuales de la naturaleza y aspectos más profundos de la naturaleza que sólo son visibles más tarde. O’Neill (1994: 27) concluye que los temas de la validez de las concepciones construidas socialmente tienen que incorporarse en los análisis, argumentando que una preocupación adecuada en referencia a la naturaleza presupone creencias verdaderas al respecto. Así, resulta fundamental no confundir «Construcciones sociales o interpretaciones con sus productos materiales o referentes» (Sayer, 1997: 482) ni quitar del análisis los poderes causales independientes de la naturaleza, porque éstos tienen efectos importantes sobre las construcciones sociales. Por ejemplo, K. O’Neill (2000) ha documentado cómo cuatro casos de seria contaminación durante las décadas de 1960 y 1970 en Japón, promovió nuevas concepciones acerca de cómo compensar a las víctimas en los juicios, lo que generó una actitud de aversión al riesgo en el Gobierno y a regulaciones estrictas con respecto a la gestión de residuos. Dickens (2001: 94) sostiene persuasivamente que "hay, por lo tanto, razones poderosas para desarrollar las ciencias sociales de manera que puedan reflejar la continua y rápida evolución de las interacciones entre la sociedad y los poderes causales de la naturaleza».

El realismo examina «la manera como el orden social encaja con y es condicionado por el orden natural del que emerge y sobre el que a su vez reacciona» (Bhaskar, 1989: 173-40). El realismo crítico (Collier, 1994; Sayer, 2000) es realismo porque integra a los poderes causales de la naturaleza, en lugar de quitarlos de su análisis. Es crítico porque entiende el conocimiento como cons- 
truido socialmente sobre la base de la cultura, el poder y la desigualdad. Precisamente por esto, así como los niveles profundos de la naturaleza no son siempre visibles en un momento determinado incluso por la ciencia, este conocimiento se considera parcial, tanto en el sentido de que es incompleto como en el sentido de que favorece a aquellos grupos que controlan su desarrollo (Murphy, 1994: capítulo 9; Dickens, 1992, 1996, 2000, 2001; Benton, 1989, $1992,1993,1994)$. En el realismo crítico, el conocimiento de la naturaleza y la percepción del riesgo son construcciones sociales problemáticas. Sayer (2001: 969) concluye que «la razón más convincente para aceptar la premisa realista básica de la independencia o de lo Otro en el mundo, es la experiencia de cometer errores, o de haber confundido las expectativas y chocar contra sorpresas inesperadas - es decir, la experiencia de la falsificación». Las sorpresas que se producen en las dinámicas naturales demuestran la necesidad de distinguir entre naturaleza y concepciones particulares de ella.

Las dinámicas autónomas de la naturaleza eventualmente producen acontecimientos y síntomas perceptibles para la capacidad sensorial humana: el acontecimiento o la perturbación climática extrema ocurre o no, tumores que aparecen a consecuencia de radiación, el abundante bacalao supuestamente desaparece, criaturas con deformidades nacen de madres que tomaron talidomida, etc. El medio ambiente es el campo de pruebas donde significados construidos socialmente impuestos a las dinámicas naturales demuestran ser o no apropiados. Esto normalmente ocurre después de un período de tiempo (Adam, $1995,1998,2000$ ), cuando incluso el riesgo que anteriormente no se percibía se torna un riesgo percibido, lo que demuestra que las condiciones materiales subyacen a las percepciones del riesgo, a la construcción social de este riesgo como problema social y a las acciones para mitigarlo. Una comunidad puede rechazar el reconocimiento del riesgo a pesar de la existencia de síntomas materiales visibles (por ejemplo, la contaminación) y definirlos como no problemáticos, en cuyo caso las dinámicas naturales determinarán las consecuencias. Para llevar a cabo una investigación en estos términos, cabe incorporar explícitamente en el análisis las relaciones entre las prácticas sociales y las dinámicas naturales, y cabe también rechazar la metodología simplificadora en exceso, atemporal y acontextual, de los que quitan las dinámicas naturales de sus análisis, para virar del constructivismo social al realismo crítico.

Los construccionistas (Burningham y Cooper, 1999: 310) malinterpretan el enfoque realista como si éste asumiera un acceso no mediado a una realidad incontestable. Los constructivistas no aciertan a entender este argumento. Los realistas están de acuerdo en que las dinámicas naturales están mediadas por categorías preexistentes en la formación de concepciones acerca de la naturaleza y que estas concepciones están disputadas. Pero el análisis realista no menosprecia lo que está siendo mediado (los procesos naturales), ni tampoco reduce la investigación al estudio únicamente del mediador. La experiencia y la observación de lo mediado (naturaleza preexistente) es tan importante como examinar las categorías culturales preexistentes. Un enfoque realista crítico que examina los significados construidos socialmente y las prácticas de los sensoriales 
y experimentales humanos en sus relaciones con las dinámicas autónomas de la naturaleza proporciona un análisis más completo y exhaustivo que un enfoque constructivista social que rechaza incorporar estas dinámicas en el análisis.

\section{La internalización de la naturaleza autónoma en la sociedad}

Eliminar la división conceptual entre las prácticas socioculturales y las dinámicas naturales mediante la fusión de ambas en una noción amorfa, probablemente no mejorará el conocimiento. Tanto la capacidad de acción de los humanos como las dinámicas naturales son creativas, pero las diferencias en el carácter de sus creatividades respectivas no deben ser oscurecidas. Una noción holística ha sido reducida, por un lado, a un determinismo biológico que ignora a las prácticas culturales, y, por el otro, a un construccionismo social que menosprecia los efectos de las dinámicas naturales. Debiera desarrollarse una concepción más precisa de la percepción de los dos.

\subsection{Naturaleza recombinante y naturaleza primaria}

Latour (1996: VIII) ha «tratado de mostrar a los investigadores de las ciencias sociales que la sociología no es la ciencia de únicamente los seres humanos - que puede dar la bienvenida a multitudes de no humanos con los brazos abiertos». Las sociedades contemporáneas utilizan instrumentos como bombas de aire, sistemas eléctricos, robots y pistones para recomponer lo social y aumentar su escala. Estos instrumentos son híbridos: construcciones de humanos y no humanos a la vez (Latour, 1991: 17). Tiene lugar un intercambio de propiedades entre los humanos y los no humanos, por ejemplo, los topes que fuerzan a los conductores a reducir la velocidad del vehículo: «algunas, aunque no todas, las características del pavimento se tornan policías, y algunas, aunque no todas, las características de los policías se tornan rampas del pavimento para reducir la velocidad ${ }^{4}$ (Latour, 1999: 190).

El enfoque de Latour remarca la influencia del mundo material sobre las prácticas sociales, las percepciones y los conocimientos. Ya que los conductores que pasan deprisa por encima de los topes se ven forzados a sufrir las consecuencias, la acción está limitada, pero no totalmente determinada por ellos. Su noción de intercambio es, no obstante, poco convincente ¿Cómo los no humanos, como los topes, «intercambian» si no tienen suficiente capacidad para establecer un intercambio intencional? O la capacidad de acción humana es atribuida erróneamente a los no humanos o los no humanos son erróneamente privados de su creatividad, al serles atribuidas solamente propiedades que los humanos les otorgan.

4. Nota del traductor: Latour aquí utiliza un juego de palabras. Dado que estas rampas para reducir la velocidad se llaman en inglés sleeping policemen, es decir, 'policías durmientes', que si bien ya forman parte de la naturaleza construida y "durmiente», en realidad actúan sobre los humanos como si se tratase de policías bien despiertos. 
Sería más adecuado teorizar la influencia de los no humanos como dinámicas de la naturaleza. Las rampas del pavimento reutilizan las fuerzas gravitacionales para que los conductores tengan una conducción incómoda más allá de cierta velocidad. Las dinámicas naturales están incrustadas en los topes, y los humanos utilizan estos procesos para ciertas prácticas definidas socialmente. El ejemplo de Latour implica lo que llamaría naturaleza recombinante: materiales y dinámicas naturales articuladas para ralentizar a conductores. Generalmente, la tecnología consiste en ensamblar la naturaleza: reorganizar los materiales y las dinámicas naturales de distintas maneras que no se encuentran en la naturaleza prístina para alcanzar objetivos determinados. Esto es verdad en la ciencia aplicada y en innovaciones de materiales por tanteo. Incluso los edificios son híbridos ensamblados: las construcciones humanas consisten en calculados equilibrios entre las fuerzas naturales y los materiales. Del mismo modo, la tecnología construida por los humanos consiste en una recombinación de sustancias y procesos creados por las fuerzas de la naturaleza. Además, esta naturaleza recombinante a menudo implica muchas más dinámicas no humanas que en el caso de las rampas de reducción de velocidad, como los motores de combustión interna, los antibióticos, la talidomida, los reactores nucleares y las bombas inteligentes. Los materiales y las dinámicas naturales integrados dentro de las construcciones materiales humanas mantienen su potencial de escaparse de los controles construidos por los humanos (Perrow, 1984).

Asimismo, los no humanos no son únicamente aquellos fabricados por los humanos. La mayoría de "las multitudes no humanas» se han producido ellas mismas, estuvieran o no presentes los humanos. Los árboles y la fotosíntesis, las bacterias y los virus, los terremotos y los acontecimientos climáticos extremos son algunos ejemplos. Yo me refiero a estos elementos como naturaleza primaria u original. Llevar las relaciones entre los humanos y los no humanos a la sociología implica investigar la articulación de los seres humanos con el mundo natural, particularmente, la interacción entre la construcción social de naturalezas recombinantes y las dinámicas de la naturaleza primaria.

No sólo las construcciones físicas, sino también las construcciones sociales son construidas utilizando híbridos, fruto de recombinaciones de dinámicas naturales. Por ejemplo, la forma contemporánea de globalización ha sido posible debido a la red de comunicaciones instantáneas basada en satélites, los cuales están construidos utilizando materiales naturales recombinados para cumplir tareas específicas, por ejemplo: paneles solares para capturar energía del sol, y los satélites colocados en una órbita especialmente calculada en un campo de fuerzas gravitacionales. La construcción social de un sistema económico, informativo y militar depende de estos satélites, que tienen relaciones con fuerzas naturales primarias, no recombinadas, como la atracción gravitacional de la Tierra y la energía emitida por el Sol. Estos satélites están, entonces, afectados por otras fuerzas naturales primarias, como las tormentas solares (Baker y otros, 1998).

Las construcciones sociales no tienen una libertad total de movimientos. Todo lo contrario, están construidas por materiales y dinámicas de la natura- 
leza recombinante y están situadas en un campo mayor de fuerzas naturales. Las sociedades mismas son híbridos compuestos por construcciones sociales y dinámicas naturales mediante 1) sustancias y procesos naturales que se recombinan para alcanzar objetivos definidos socialmente y 2) relaciones entre esta naturaleza recombinante y fuerzas naturales de mayor alcance, como anteriormente las áreas prístinas fueron modificadas por la actividad humana. Así, un marco relacional que examina la interacción entre las prácticas sociales y las dinámicas autónomas de la naturaleza es más apropiado que el constructivismo social extremo, el cual separa las dinámicas naturales, o que el determinismo biológico, el cual separa las dinámicas sociales. A medida que las prácticas sociales se extienden hacia lo que era naturaleza prístina y recompone lo social utilizando híbridos construidos por humanos y por procesos naturales, la naturaleza prístina es sustituida por la naturaleza primaria (dinámicas naturales autónomas de mayor alcance que operan sobre y dentro de las construcciones humanas) y la naturaleza recombinante (tecnología). Nuevas relaciones entre las prácticas sociales y las dinámicas naturales emergen, a menudo en formas constructivas, en formas amenazadoras otras veces.

Cabe destacar que estas concepciones de la naturaleza prístina, primaria y recombinante son construidas socialmente, como es el caso de otras distinciones establecidas por investigadores (por ejemplo, Frank, 1997) y como lo es también la misma concepción de "construccionismo social». Estas concepciones se presentan aquí como parte del argumento de que las dinámicas naturales están siendo internalizadas por la sociedad y de que las relaciones entre las prácticas sociales y las dinámicas naturales deberían ser estudiadas, en lugar de ser puestas entre paréntesis. Estas distinciones deben ser juzgadas, como otras concepciones en investigación, por su coherencia teórica y su utilidad empírica para avanzar en el conocimiento hasta ahora menospreciado de su influencia en las ciencias sociales.

\subsection{Ejemplos del cambio de naturaleza prístina a la primaria y recombinante}

En junio de 1908, un meteorito en llamas cayó en el norte de Siberia y explotó en la remota Tunguska, arrasó $2.000 \mathrm{~km}^{2}$ de bosque y produció una onda de choque atmosférica que dio dos vueltas al planeta. Hubo pocas víctimas humanas, si acaso alguna, porque el impacto ocurrió en una región deshabitada. Se estimó que el meteorito pesaba unos cuantos millares de toneladas y hacía alrededor de 60 metros de diámetro. El conocimiento actual sugiere que un meteorito de este tamaño colisiona con la Tierra una vez cada centenario y que un meteorito de un metro colisiona con nuestro planeta cada hora (Zebrowski, 1997: 216-25). Encuentros por poco entre la órbita terrestre y la de grandes asteroides son frecuentes: un asteroide de 1.000 metros estaba en el mismo punto en el espacio que nuestro planeta en un intervalo de seis horas en

5. Nota del traductor: en la versión inglesa decía «pristine, primal and recombinant nature». 
1989 y en un intervalo de cuatro horas en 1996. Mientras el planeta era fundamentalmente virgen, incluyendo el espacio a su alrededor, el peligro para los humanos y sus construcciones era muy reducido. Antes de que la ciencia fuera desarrollada, los humanos no percibían el riesgo. Pero, a medida que las poblaciones se multiplicaron y las construcciones humanas llenaron la mayoría de las áreas terrestres, a medida que los satélites fueron instalados en el espacio y las comunicaciones se hicieron dependientes de ellos, las probabilidades y las consecuencias de colisiones con objetos extraterrestres creció significativamente. Las percepciones del riesgo crecen también a medida que la ciencia proporciona mejores medidas para detectarlas. Estas fuerzas de la naturaleza están siendo incorporadas a la sociedad en términos tanto de experiencia como de percepción del riesgo, a medida que la naturaleza prístina es sustituida por naturaleza primaria ocupada socialmente y a medida que la naturaleza recombinante (ciencia y tecnología) se construye socialmente.

En 1988, un terremoto de baja intensidad (Richter 6,8) mató a 55.000 personas en Armenia, mientras que uno en 1964 en Alaska que liberó varios centenares más de energía (Richter 9,3), mató a 131 personas (Zebrowski, 1997: 293). Alaska no estaba mejor preparada que Armenia frente a un terremoto. Más bien Armenia había sido transformada de región virgen a territorio densamente poblado, con lo que se incorporaron los terremotos a la sociedad de Armenia. Los Estados Unidos habían dejado Alaska en gran medida como región virgen y deshabitada, por lo tanto, los terremotos de Alaska no habían sido internalizados en la sociedad americana.

Hay buenas evidencias para pensar que los terremotos más fuertes en la historia americana ocurrieron en Missouri en 1811 y 1812 (Zebrozski, 1997: 190-1). El curso de los ríos cambió, extensas modificaciones del nivel del suelo tuvieron lugar, se originó un tsunami en el río Mississippi que temporalmente invirtió su curso, que pasó a desembocar en depresiones de recién formación que aún en la actualidad siguen siendo lagos. Los efectos se sintieron a casi $2.000 \mathrm{~km}$ de distancia en Boston. No hubo, sin embargo, grandes pérdidas de vidas o destrozos materiales, porque la región era prácticamente virgen. Éste no es el caso en la actualidad. Una repetición del suceso hoy en día implicaría una catástrofe de grandes dimensiones, pues el área está mucho más poblada, está cruzada por infinidad de infraestructuras como tuberías, líneas de transmisión eléctrica, carriles ferroviarios, carreteras, rutas navales y desembarcaderos en el río Mississippi. No fueron instaladas defensas costosas, pues han pasado 190 años sin que otro terremoto haya ocurrido de nuevo, y aparentemente no había ninguna falla geológica, por lo tanto, las probabilidades se asumieron como bajas. A pesar de todo, si se tienen en cuenta períodos largos de tiempo, las probabilidades están lejos de ser insignificantes: "cuando ocurra el próximo terremoto en la costa este, la región afectada será cogida totalmente de desprovisto» (Zebrowski, 1991: 190). Ahora, la falla ha sido descubierta: ha sido llamada la «zona sísmica de New Madrid», la cual transcurre a través de Arkansas, Missouri, Tennessee, Kentucky y Illinois. 
A medida que los humanos transforman lo salvaje y prístino en un medio ambiente reconstruido socialmente e incrementan sus poblaciones, exponen sus comunidades a las fuerzas de la naturaleza. "La naturaleza no es un reino separado de los humanos [...] sino lo contrario es [...] un sistema de conexiones e interacciones altamente vulnerable a perturbaciones, del que los humanos inextricablemente dependen" (Worster, 1994: 350). La historia de los terremotos demuestra que la mayoría de fatalidades han ocurrido en países las poblaciones de los cuales crecieron, en un principio, donde las medidas de protección eran inadecuadas, y que la mortalidad ha tendido a decrecer a medida que han mejorado las tecnologías protectoras. Una lista de terremotos que mató a 100.000 personas o más incluye Siria (año 526), 250.000 muertos; China (1290), 100.000; China (1556), 830.000; Japón (1730), 137.000; India (1738), 300.000; Italia (1908), 120.000; China (1920), 100.000; Japón (1923), 200.000; China (1927), 200.000, y China (1976), 242.000 (Zebrowski, 1997: apéndice B). Cuando la naturaleza prístina se reconstruye en comunidades humanas, se torna crucial percibir el riesgo apropiadamente y hacer construcciones sociales (edificios en el caso de los terremotos) que tengan en cuenta la interacción con las dinámicas naturales, porque estas dinámicas han sido internalizadas dentro de la sociedad.

Hubo un tiempo en que los icebergs flotaban sin peligro alguno desde el Ártico bajando por las costas del Nuevo Mundo antes de derretirse en aguas del sur. A medida que se fueron construyendo las líneas de navegación entre Europa y Norteamérica, los barcos pasaron a estar expuestos a estas fuerzas de la naturaleza, como demostró lo sucedido con el Titanic. Ya que nada pudo hacerse con los icebergs, los barcos únicamente podían protegerse mediante un sistema de seguimiento que, en la actualidad, utiliza el GPS de los satélites. Construcciones sociales recientes se han extendido en este corredor de icebergs con la instalación de plataformas de extracción de petróleo. Se han implementado protecciones contra colisiones con icebergs próximos, pero existe la incertidumbre acerca de si estas defensas construidas socialmente serán capaces de salvaguardar todos los aparejos petrolíferos de estas enormes construcciones móviles de la naturaleza primaria.

La necesidad de protegerse contra las perturbaciones de la naturaleza afecta a la humanidad en su conjunto, lo que nos conduce al tema de la justicia ambiental. Algunas fuerzas de la naturaleza son tan globales, todopoderosas e impredecibles que incluso los ricos se convierten en sus víctimas; algunas veces son especialmente los ricos quienes sobrevaloran su capacidad tecnológica para abolir la autonomía de la naturaleza, de manera que toman ellos mismos caminos peligrosos (casas en acantilados mirando al mar, etc.). La destrucción natural de Galvestone en 1900 no exoneró a los ricos (Larson, 2000). Pero, normalmente, es la gente sin medios para protegerse de las perturbaciones naturales la que más sufre, incluso en sociedades prósperas. Klinenberg (1999: 242) documentó los días límite de la ola de calor de Chicago en 1995 considerando «como el clima, las condiciones de vida de los ciudadanos más precarios, y el gobierno local, [...] interaccionaron para determinar los niveles de peligro 
y daño que un desastre como la ola de calor inflige». A pesar de su título «Desnaturalizando el desastre», su estudio es muy diferente a los que excluyen a las dinámicas naturales.

\subsection{Los peligros de la naturaleza recombinante}

La internalización en la sociedad de nuevos procesos autónomos de la naturaleza ocurre no sólo espacialmente (invadiendo áreas vírgenes), sino también a través del rediseño de procesos naturales. Cuando es manipulada por la ciencia aplicada, la naturaleza ni se construye socialmente ni es abolida. En lugar de ello, los procesos de todo lo que se ha vuelto a ensamblar constituyen los elementos mismos de las construcciones sociales y técnicas. La utilización de estos híbridos, parcialmente construidos por humanos y parcialmente por no humanos, se basa en el supuesto que pueden controlarse, pero la latente autonomía inherente en estos instrumentos de la naturaleza recombinante conlleva nuevos peligros. Colborn y otros (1996: 241-2) documentaron cómo productos químicos diseñados para llevar a cabo tareas determinadas desencadenaban dinámicas naturales inesperadas que ponían en peligro a los humanos: «Una y otra vez, ellos [los inspectores de pesticidas] han prohibido productos químicos por el reciente reconocimiento del peligro que conllevan, el cual es solamente oscurecido por peligros que ellos nunca pensaron en anticipar». Los híbridos implican el riesgo de que sus dinámicas no humanas puedan escapar del control y explotar (fábricas químicas), mutar (formas de vida modificadas genéticamente), corroerse (tuberías de gas), etc. La naturaleza tiene sus propios procesos destructivos y constructivos, que conservan sus fuerzas potencialmente autónomas incluso cuando son reensamblados e incorporados en construcciones humanas. Estos procesos tienen la capacidad de reventar en pedazos las construcciones humanas desde dentro. Por ejemplo, en un medio ambiente prístino, el 99,3 por ciento de U-238 en uranio metal impide la reacción de fisión del 0,7 por ciento de U-235 desde el principio, pero cuando el segundo es concentrado en reactores nucleares, la masa crítica produce no sólo energía eléctrica, sino también una potente explosión y residuos altamente radioactivos, la dinámica autónoma de los cuales se incorpora a la sociedad.

La utilización de naturaleza recombinante conlleva también interacciones impredecibles y peligrosas con la naturaleza primaria. La construcción de una red de distribución eléctrica centralizada en el noreste de Norteamérica y la confianza en ella para infraestructuras esenciales -incluyendo la calefacción en un clima de invierno oscuro y frío - incrementa la vulnerabilidad frente a la lluvia congelante, lo que resultó en enero de 1998 en la aparición del más costoso desastre nunca habido en la historia de Canadá (Murphy, 2001 y de próxima publicación). La naturaleza recombinante también amenaza de alterar mecanismos de autorregulación de la naturaleza primaria. Los fertilizantes químicos lideraron la revolución verde, pero, a largo plazo, degradaron el suelo. La aplicación de DDT redujo en gran medida la malaria, pero era un agente cata- 
lizador para el desarrollo de agentes cancerígenos. El uso de antibióticos como medicamentos milagro promovieron la emergencia de bacterias particularmente resistentes. La utilización de energías fósiles produce el cambio climático global, con efectos en la sociedad que son inciertos aunque amenazadores. La sociedad moderna ha internalizado la naturaleza sin ser capaz de abolirla como el otro autónomo de la sociedad. De este modo, la sociedad se ha generado a sí misma nuevos riesgos de naturaleza recombinante, de la que la sociedad se ha convertido en dependiente, $y$ ha perturbado a la naturaleza primaria, de la cual también depende.

\subsection{Gestionar la naturaleza recombinante en el contexto de la naturaleza primaria}

Tenner se mantiene optimista en considerar que los efectos venganza de la naturaleza puedan ser compensados por los beneficios del reensamblaje tecnológico de sus procesos. Su optimismo, no obstante, viene condicionado. «Optimismo tecnológico quiere decir, en la práctica, la habilidad de reconocer las malas sorpresas con suficiente antelación como para permitir que se pueda hacer algo. Y esto exige un seguimiento constante del globo y de cualquier cosa, desde cambios en las temperaturas medias y particulares hasta tráfico de bacterias y virus» (Tenner, 1997: 353-4). Puesto que la interacción con los procesos independientes de la naturaleza continúa, el optimismo está justificado sólo si la vigilancia es alta, los riegos percibidos y las acciones defensivas se llevan a cabo. Pero esto no significa fuerza tecnológica bruta para reconstruir la naturaleza, lo que solamente exacerbaría su efecto venganza. Las viejas ilusiones de abolir la naturaleza o de construirla tendrán que ser sustituidas. Ejemplar sería el ayudar a las bacterias letales a evolucionar en compañía y hasta un estado que no supusieran un peligro en lugar de sobreutilizar antibióticos para tratar de eliminarlas (Ewald, 1994). El optimismo debe ser temperado únicamente por un solo factor. Cuando las fuerzas autónomas de la naturaleza son incorporadas a la sociedad mediante la expansión de la sociedad hacia áreas prístinas y la recombinación de dinámicas naturales, incluso la tecnología más avanzada no proporciona siempre: 1) la capacidad de reconocer las malas sorpresas de la naturaleza tempranamente ni 2) la capacidad de evitarlas. El poder de la naturaleza de producir perturbaciones que sorprendan a los expertos y a los no expertos se ha ido confirmando repetidamente (ver Murphy, 1999).

La internalización de la naturaleza autónoma en la sociedad moderna ha tenido lugar no sólo de un modo peligroso, sino también positivo. Las regiones vírgenes han sido incorporadas a la sociedad, salvaguardadas por leyes como parques naturales. Se han tomado medidas para proteger los bosques, los lagos y los ríos de la lluvia ácida construida socialmente. La capa de ozono ha sido integrada a la sociedad de modo que tanto ella como sus funciones beneficiosas fueron hechas visibles y protegidas. La ciencia nos ha permitido ver partes de la naturaleza que anteriormente permanecían invisibles. 


\section{Conclusión}

La «construcción social de la naturaleza» y la «abolición de la naturaleza» son expresiones abstractas que tienen poco que ver con la naturaleza misma. Más bien tienen que ver con la construcción social y la abolición de concepciones particulares de la naturaleza y la abolición de su carácter prístino.

Las concepciones culturales de la naturaleza (y del riesgo) son de hecho importantes y determinan las prácticas sociales. Estas concepciones constituyen construcciones sociales que son tan reales (particularmente en sus consecuencias) como cualquier otra cosa que la naturaleza haya creado. Se trata de reconocer esto sin desviar la atención de las limitaciones y dinámicas creadas por los procesos naturales, los cuales también afectan a las prácticas y a las concepciones sociales. Los procesos autónomos de la naturaleza interactúan con las construcciones sociales, de tal modo que, en la actualidad, las segundas han eliminado a las áreas vírgenes de nuestro planeta, modificando toda su biosfera e internalizando nuevas dinámicas naturales en la sociedad. La naturaleza prístina ha sido sustituida por una naturaleza primaria acompasada socialmente, pero que mantiene la misma capacidad que las dinámicas independientes.

Asimismo, la tecnología es más bien la manipulación y el reensamblaje de las dinámicas naturales que la construcción social o abolición de la naturaleza. Los instrumentos tecnológicos son híbridos de construcciones humanas y creaciones naturales. La naturaleza permanece encajada con la tecnología, al igual que lo hace su potencial para escapar del control. Las nuevas dinámicas emergentes de la naturaleza han sido integradas a la sociedad a través del desarrollo tecnológico, algunas veces de modo intencionado y otras, como fruto de consecuencias no intencionadas. Además, las dinámicas de la naturaleza, ahora reorganizadas con instrumentos tecnológicos, afectan de nuevo a procesos fundamentales más amplios de la naturaleza. Estas interacciones entre la naturaleza recombinante y la naturaleza primaria tienen repercusiones materiales para las construcciones sociales. El resultado es que ahora los humanos deben gestionar estas dinámicas naturales «aquí mismo». Esta gestión es compleja, costosa y crónica (Tenner, 1997). Es de momento incierto saber si los humanos son capaces de llevar a cabo esta tarea.

En algunos casos, las dinámicas naturales que afectan a las prácticas sociales se originan en la naturaleza misma (naturaleza primaria), en otros casos provienen del reensamblaje humano de los procesos naturales (naturaleza recombinante), pero en los dos casos no pueden reducirse a una construcción social. Debido a que nuevos procesos naturales primarios y recombinantes se han incorporado a la sociedad, hay una razón aún mayor para incorporar las dinámicas naturales en el análisis sociológico.

\section{Agradecimientos}

Me gustaría agradecer al Social Sciences and Humanities Research Council of Canada la financiación de esta investigación. También me gustaría dar las gra- 
cias a dos revisores anónimos y a los editores de The Sociological Review por sus inestimables comentarios.

\section{Bibliografía}

ADAm, B. (1995). Timewatch: The Social Analysis of Time. Cambridge: Polity Press.

- (1998). Timescapes of Modernity: The Environment and Invisible Hazards. Londres: Routledge.

- (2000). «The Media Timescapes of BSE News». En: Allan, S.; AdAM, B.; CARTER, C. (eds.). Environmental Risks and the Media. Londres: Routledge, p. 117-29.

Baker, D.; Allen, J.; KaneKal, S.; Reeves, G. (1998). «Pager Satellite Failure May Have Been Related to Disturbed Space Environment». Eos, vol. 79, octubre 6: 477.

BecK, U. (1992). Risk Society: Towards a New Modernity. Londres: Sage.

- (1995). Ecological Politics in an Age of Risk. Cambridge: Polity Press.

BeCKeRMAn, W. (1974). In Defense of Economic Growth. Londres: Jonathan Cape. Benton, T. (1989). «Marxism and Natural Limits». New Left Review, 178: 51-86.

- (1991). «Biology and Social Science». Sociology, 25: 1-29.

- (1992). «Ecology, Socialism, and the Mastery of Nature: A Reply to Reiner Grundmann». New Left Review, 194: 55-74.

- (1993). Natural Relations. Londres: Verso.

- (1994). «Biology and Social Theory in the Environmental Debate». En: RedClifT, M.; Benton, T. (eds.). Social Theory and the Global Environment. Londres: Routledge, p. 28-50.

BHASKAR, R. (1978). A Realist Theory of Science. Brighton: Harvester Press.

- (1979). The Possibility of Naturalism. Harvester Wheatsheaf: Hemel Hempstead.

- (1989). Reclaiming Reality. Londres: Verso.

Bluhdorn, I. (1997). «A Theory of Post-Ecologist Politics». Environmental Politics, 6: $125-47$.

Burningham, K.; CoOper, G. (1999). «Being Constructive: Social Constructionism and the Environment». Sociology, 33: 297-316.

CapeK, S. (1993). «The «Environmental Justice Frame». Social Problems, 40: 5-24.

CARSON, R. (1962). Silent Spring. Boston: Houghton Mifflin.

Colborn, T.; Myers, J. P.; Dumanoski, D. (1996). Our Stolen Future. Boston: Little, Brown \& Company.

Collier, A. (1994). Critical Realism. Londres: Verso.

Collins, H. (1981). «Stages in the Empirical Programme of Relativism». Social Studies of Science, 11: 3-10.

Collins, H.; Pinch, T. (1979). "The Construction of the Paranormal: Nothing Unscientific is Happenin». En: Wallis, R. (ed.). On the Margins of Science. University of Keele: Sociological Review Monograph núm. 27, p. 237-70.

DiCKENS, P. (1992). Science and Nature. Philadelphia: Temple University.

- (1996). Reconstructing Nature: Alienation, Emancipation and the Division of Labour. Londres: Routledge.

- (2000). Social Darwinism. Buckingham: Open University Press.

- (2001). «Linking the Social and Natural Sciences». Sociology, 35: 93-110.

DUNLAP, R.; CATTON, W. (1994). «Struggling With Human Exemptionalism». American Sociologist, 25: 5-30. 
Dunlap, R.; Scarce, R. (1991). «The Polls-Poll Trends». Public Opinion Quarterly, 55: 651-72.

EDER, K. (1996). The Social Construction of Nature. Londres: Sage.

Evernden. N. (1993). The Social Creation of Nature. New Haven: Yale University Press.

Ewald, P. (1994). Evolution of Infectious Disease. Nueva York: Oxford University Press. FranK, D.J. (1997). «Science, Nature, and the Globalization of the Environment». Social Forces, 76: 409-37.

Giddens, A. (1991). Modernity and Self-Identity. Cambridge: Polity Press.

Grundmann, R. (1991a). «The ecological challenge to Marxism». New Left Review, 187: 103-120.

- (1991b). Marxism and Ecology. Oxford: Oxford University Press.

- (2001). Transnational Environmental Policy: Reconstructing Ozone. Londres: Routledge.

Hamilton, D. (1973). Technology, Man and the Environment. Londres: Faber and Faber.

HanNigan, J. (1995). Environmental Sociology. Londres: Routledge.

KLINENBERG, E. (1999). «Denaturalizing disaster: A social autopsy of the 1995 Chicago heat wave». Theory and Society, 28(2): 241.

LARSON, I. (2000). Isaac's Storm. Nueva York: Vintage.

LaTOUR, B. (1991). Nous n'avons jamais été modernes. París: La Découverte.

- (1996). Aramis or the Love of Technology. Cambridge, Ma.: Harvard University Press.

- (1999). Pandora's Hope. Cambridge, Ma.: Harvard University Press.

Latour, B.; Woolgar, S. (1986). Laboratory Life. Segunda edición. Princeton:

Princeton University Press.

LiksDOG, R. (1996). «In Science We Trust?». Acta Sociologica, 39: 31-51.

MaCnaghten, P.; URrY, J. (1998). Contested Natures. Londres: Sage.

MaddoX, J. (1972). The Doomsday Syndrome. Londres: Macmillan.

MCKibBEn, B. (1990). The End of Nature. Nueva York: Random House.

Merchant, C. (1980). The Death of Nature. San Francisco: Harper Collins.

Mitchell, R.C. (1990). «Public Opinion and the Green Lobby». En: ViG, N.J.;

KRAFT, M.E. (eds.). Environmental Policy in the 1990s. Washington: CQ Press, p. 81-99.

MuRDOCH, J. (2001). «Ecologising Sociology». Sociology, 35: 111-33.

MurPHY, R. (1994). Rationality and Nature. Boulder: Westview.

- (1997). Sociology and Nature: Social Action in Context. Boulder: Westview.

- (1999). "Unperceived Risk: The Great 1998 Ice Storm in Northeastern North America». Advances in Human Ecology, 8: 99-123.

- (2001). «Nature's Temporalities and the Manufacture of Vulnerability». Time and Society, 10: 329-48.

- (2002). «Extreme Weather and the Energy Metabolism of the City». Environment and History, 8: 43-64.

O’NeILL, J. (1994). «Humanism and Nature». Radical Philosophy, 66: 27.

O’NeILl, K. (2000). Waste Trading among Rich Nations. Cambridge, Mass.: MIT Press. Perrow, C. (1984). Normal Accidents. Nueva York: Basic.

SAYER, A. (1992). Method in Social Science: A Realist Approach. Londres: Routledge.

- (1997). «Essentialism, social constructionism, and beyond». The Sociological Review, 45(3): 453-87. 
- (2000). Realism and Social Science. Londres: Sage.

- (2001). «Reply to Holmwood». Sociology, 35: 967-84.

SCHMIDT, V. (2001). "Oversocialised Epistemology: A Critical Appraisal of Constructivism». Sociology, 35: 135-57.

SimON, J. (1981). The Ultimate Resource. Princeton: Princeton University Press.

SismondO, S. (1993). «Some Social Constructions». Social Studies of Science, 23: 51553.

SJOBERG, L. (ed.) (1987). Risk and Society. Boston: Allen \& Unwin.

SOPER, K. (1995). What is Nature? Oxford: Blackwell.

Tenner, E. (1997). Why Things Bite Back. Nueva York: Vintage.

TeSTER, K. (1991). Animals and Society. Londres: Routledge.

VaYK, J. P. (1978). Doomsday Has Been Cancelled. Menlo Park, Ca.: Peace Publishers. WoOlgar, S. (1988). Science: The Very Idea. Londres: Routledge.

Worster, D. (1994). Nature's Economy. Cambridge: Cambridge University Press. Zebrowski, E. Jr. (1997). Perils of a Restless Planet. Cambridge: Cambridge University Press. 